The Summer Undergraduate Research Fellowship (SURF) Symposium

7 August 2014

Purdue University, West Lafayette, Indiana, USA

\title{
Development of Combined Dual-Pump Vibrational and Pure- Rotational Coherent Anti-Stokes Raman Scattering (DPVCARS and PRCARS) System
}

Shenli Yuan, Aman Satija and Robert P. Lucht

School of Mechanical Engineering, Purdue University

\begin{abstract}
Coherent anti-Stokes Raman scattering (CARS) [1,2] is a spatially-resolved, time-resolved spectroscopic technique for quantitative measurements in reacting flows [3-6]. This work demonstrates a combination of $\mathrm{N}_{2} / \mathrm{O}_{2} / \mathrm{CO}_{2}$ dual-pump vibrational coherent anti-Stokes Raman scattering (DPVCARS) system and two-beam pure-rotational coherent anti-Stokes Raman scattering (PRCARS) system. It is based on the previous development of combined VCARS and PRCARS system which was used to obtain temperature measurements in non-premixed $\mathrm{H}_{2}$-air flames. The new combined system will be used to measure the temperature profiles and major species concentrations such as $\mathrm{N}_{2} / \mathrm{O}_{2} / \mathrm{CO}_{2}$ in laminar counter-flow non-premixed $\left(\mathrm{CH}_{4} / \mathrm{Air}\right)$ and partiallypremixed $\left(\mathrm{CH}_{4} / \mathrm{H}_{2} /\right.$ Air) flames. The new system is being characterized in $\mathrm{H}_{2} /$ Air diffusion flames stabilized over a Hencken burner. $\mathrm{CO}_{2}$ will be added to the oxidizer stream for the system to assess the precision of the system while performing concentration measurements. The new combined system has shown good precision temperature using PRCARS (better than $3 \%$ ) and $\mathrm{N}_{2} / \mathrm{O}_{2}$ mole-fraction ratio (better than $5 \%$ ) using DPVCARS.
\end{abstract}

\section{KEYWORDS}

Laser spectroscopy, combustion, nonlinear optics, Coherent anti-Stokes Raman scattering

\section{REFERENCES}

[1] Eckbreth A. C., "Laser diagnostics for combustion temperature and species", Amsterdam: Gordon and Breach (1996).

[2] Roy S., Gord J. R., and Patnaik, A. K., "Recent advances in coherent anti-Stokes Raman scattering spectroscopy: Fundamental developments and applications in reacting flow", Progress in Energy and Combustion Science, Vol. 36, 280-306 (2010).

[3] Reginer P. R. and Taran J. P. E., "On the possibility of measuring gas concentrations by stimulated antiStokes scattering", Applied Physics Letters, Vol. 23, No. 5, 240-242 (1973).

[4] Barrett J. J., "Generation of coherent anti-Stokes rotational Raman radiation in hydrogen gas", Applied Physics Letters, Vol. 29, No. 11, 722-724 (1976).

[5] Eckbreth A. C. and Anderson T. J., "Simultaneous rotational coherent anti-Stokes Raman spectroscopy with arbitrary pump-Stokes spectral separation”, Optics Letters, Vol. 11, No. 8, $496-498$ (1986).

[6] Alden M., Bengtsson P. E., Edner H., Satija A. and Lucht R, "Rotational CARS generation through a multiple four-color interaction", Applied Optics, Vol. 25, No. 23, 4493-4500 (2013). 